\title{
Date of Last Immunotherapy Treatment
}

National Cancer Institute

\section{Source}

National Cancer Institute. Date of Last Immunotherapy Treatment. NCI Thesaurus.

Code C157446.

The date of the last immunotherapy treatment. 